Relations industrielles

Industrial Relations

\title{
Bureau international du Travail, La conciliation dans les conflits du travail
}

\section{Raynald Bourassa}

Volume 46, numéro 2, 1991

URI : https://id.erudit.org/iderudit/050686ar

DOI : https://doi.org/10.7202/050686ar

Aller au sommaire du numéro

Éditeur(s)

Département des relations industrielles de l'Université Laval

ISSN

0034-379X (imprimé)

1703-8138 (numérique)

Découvrir la revue

Citer ce compte rendu

Bourassa, R. (1991). Compte rendu de [Bureau international du Travail, $L a$ conciliation dans les conflits du travail]. Relations industrielles / Industrial Relations, 46(2), 487-487. https://doi.org/10.7202/050686ar

Tous droits réservés @ C Département des relations industrielles de l'Universite Laval, 1991
Ce document est protégé par la loi sur le droit d'auteur. L’utilisation des services d'Érudit (y compris la reproduction) est assujettie à sa politique d'utilisation que vous pouvez consulter en ligne.

https://apropos.erudit.org/fr/usagers/politique-dutilisation/ 
will international capital and non-state corporations place workers and communities under siege until society faces "the exhaustion of an ideal and the perversion of the current structure of decentralized labor-management relations?"

Martin J. MORand

Indiana University of Pennsylvania

La conciliation dans les conflits du travail, par le BUREAU INTERNATIONAL DU TRAVAIL, Genève, 1988, 148 p., ISBN 92-2-201007-8.

Cette publication du Bureau international du Travail se veut un guide pratique pour encourager le règlement ordonné des conflits du travail. Ce document ne traite pas du cadre juridique de la conciliation mais plutôt du processus dans lequel cette conciliation doit s'effectuer dans la dynamique des attitudes, des comportements et des approches qui permettront aux personnes mandatées à jouer le rôle de conciliateur d'intervenir avec plus d'efficacité, et par conséquent avec plus de succès. Il s'agit donc d'un ouvrage purement didactique destiné à des fins pédagogiques et il est particulièrement plus adapté aux pays en développement qu'à ceux possédant un régime de rapports collectifs du travail structuré et dont les intervenants sont expérimentés en matière de conciliation ou mieux en matière de négociation collective assistée.

Le document est divisé en 12 chapitres que nous pouvons regroupés sous trois grands thèmes. Le premier nous permet de situer la notion de conciliation et présente succintement ce que devrait être un conciliateur ainsi que les principales habiletés et qualités que cette personne doit posséder pour avoir du succès.

Le second thème brosse les étapes de la préparation d'une conciliation. En fait il s'agit des informations que doit maîtriser le conciliateur ainsi qu'une description de la logistique inhérente à son travail soit: les contacts avec les parties, les réunions et leur conduite, les séquences de la conciliation.

Le troisième volet présente certaines techniques de conciliation mais uniquement liées aux habiletés personnelles du conciliateur. D'ailleurs l'ensemble du document laisse percevoir la très grande importance que les auteurs ont octroyé aux qualités personnelles de la personne qui fait de la conciliation.

Somme toute une publication du Bureau international du Travail qui permettra, non seulement au pays en développement, mais également aux novices de ce milieu de tous les pays industrialisés, de comprendre et de mieux saisir les différentes dimensions de la conciliation. Elle pourra aussi servir de point de repère et de rafraichissement au plan de l'éthique professionnelle à tous les spécialistes des rapports collectifs du travail.

Raynald Bourassa

InnovAccord

Les limites du partenariat. Les expériences sociales-démocrates de gestion économique en Suède, en Allemagne, en Autriche et en Norvège, par Louis GILL, Montréal, Boréal, 1989, 151 p., ISBN 2-89052-292-X.

Alors qu'on assiste au plan mondial à d'intenses mutations au sein des deux grandes économies dominantes (socialiste et capitaliste), le livre de Louis Gill tombe à point afin d'alimenter la réflexion sur la recherche de nouveaux types d'économies plus démocratiques, humaines et équilibrées. 